\title{
LC-MS/MS determination of potential endocrine disruptors of cortico signalling in rivers and wastewaters
}

Journal Article

Author(s):

Ammann, Adrian A.; Macikova, Petra; Groh, Ksenia J.; Schirmer, Kristin; Suter, Marc J.-F.

Publication date:

2014-11

Permanent link:

https://doi.org/10.3929/ethz-b-000093759

Rights / license:

In Copyright - Non-Commercial Use Permitted

Originally published in:

Analytical and Bioanalytical Chemistry 406(29), https://doi.org/10.1007/s00216-014-8206-9 


\title{
LC-MS/MS determination of potential endocrine disruptors of cortico signalling in rivers and wastewaters
}

\author{
Adrian A. Ammann - Petra Macikova • Ksenia J. Groh • \\ Kristin Schirmer • Marc J. F. Suter
}

Received: 30 May 2014 / Revised: 10 September 2014 / Accepted: 19 September 2014 / Published online: 7 October 2014

(C) Springer-Verlag Berlin Heidelberg 2014

\begin{abstract}
A targeted analytical method was established to determine a large number of chemicals known to interfere with the gluco- and mineralocorticoid signalling pathway. The analytes comprise 30 glucocorticoids and 9 mineralocorticoids. Ten out of these corticosteroids were primary metabolites. Additionally, 14 nonsteroids were included. These analytes represent a broader range of possible adverse modes of action than previously reported. For the simultaneous determination of these structurally diverse compounds, a singlestep multimode solid-phase extraction and pre-concentration was applied. Extracts were separated by a short linear HPLC gradient (20 min) on a core shell RP column $(2.7 \mu \mathrm{m}$ particle size) and compounds identified and quantified by LC-MS/ MS. The method provided excellent retention time reproducibility and detection limits in the low nanograms per litre range. Untreated hospital wastewater, wastewater treatment plant influent, treated effluent and river waters were analysed to demonstrate the applicability of the method. The results show that not all compounds were sufficiently eliminated by the wastewater treatment, resulting in the presence of several steroids ( $20 \mathrm{ng} / \mathrm{L})$ and nonsteroids in the final effluent, some
\end{abstract}

A. A. Ammann $(\bowtie) \cdot$ K. J. Groh · K. Schirmer · M. J. F. Suter Department of Environmental Toxicology, Eawag, Swiss Federal Institute of Aquatic Science and Technology, 8600 Duebendorf, Switzerland

e-mail: adrian.ammann@eawag.ch

P. Macikova

Faculty of Science, RECETOX, Masaryk University, 62500 Brno, Czech Republic

K. Schirmer

School of Architecture, Civil and Environmental Engineering, EPF

Lausanne, 1015 Lausanne, Switzerland

K. Schirmer • M. J. F. Suter

Department of Environmental Systems Science, ETH Zürich, 8092 Zürich, Switzerland of them at high concentrations up to $200 \mathrm{ng} / \mathrm{L}$. Most of the detected mono-hydroxylated steroidal transformation products were found at significantly higher concentrations than their parent compounds. We therefore recommend to include these potentially bioactive metabolites in environmental toxicity assessment.

Keywords Environmental endocrine disruptors . Corticosteroid signalling pathway $\cdot$ Pharmaceuticals . Metabolites $\cdot$ Surface water

\section{Introduction}

For almost two decades, endocrine disrupting chemicals (EDCs) occurring in the aquatic environment have been the focus of environmental research, with estrogenic and androgenic compounds receiving most of the attention. They were found, for example, to reduce fertility and lead to intersex and sexual malformations in humans [1] and in wild animals [2, 3]. Yet, evidence accumulates that endocrine disruption can be caused by other groups of compounds as well. One hypothesis is that pharmaceuticals and other chemicals acting on the gluco- and mineralocorticoid signalling pathway are of concern due to their widespread use and potential adverse effects on organisms in the environment [4-6].

Reports on glucocorticoid receptor (GR) agonist, found at concentrations surpassing those of xeno-estrogens in environmental waters, underline such concerns [7-9]. GR-active and mineralocorticoid receptor (MR) active compounds, highly used in human and animal therapeutic applications, reach the aquatic environment because of their incomplete elimination during wastewater treatment. Based on consumption data in the UK, expected mean environmental concentrations of $30 \mathrm{ng} / \mathrm{L}$ and higher were calculated for the River Thames [10] for the sum of all prescribed glucocorticoids (GCs). Of 
course, type and amount of compounds can be expected to vary depending on country-specific drug approvals and treatment of different illnesses. However, a considerable abuse of GCs in doping (GCs are among the most frequently detected doping agents [11]) and non-declared additives in cosmetics also have to be expected [12]. Mineralocorticoids (MCs) are widely used in human blood pressure control [13]. The agonist potency of synthetic GCs compared to cortisol was increased by introducing halogens $(\mathrm{Cl}, \mathrm{F})$ in the steroid skeleton in order to extend their half-lives in human and animal tissues [14]. Such modifications, however, also make them less susceptible to degradation in sewage treatment processes and in the environment. This can explain the much lower elimination rate [15] and higher biological GR-mediated activity [6] found in sewage treatment plant effluents compared to estrogens. Even so, expected environmental concentrations are in the low nanograms per litre to micrograms per litre range, requiring trace analytical techniques to be applied, which means an extraction and pre-concentration step, followed by liquid chromatography-tandem mass spectrometry (LC-MS/MS) as the method of choice [16].

All methods published so far only determined a small number of GCs and only rarely MCs. For example, a study performed in The Netherlands quantified $17 \mathrm{GCs}$ and $1 \mathrm{MC}$ in wastewater [7]. In China, six GCs and one MC were found in various waters [17, 18]; in France, ten GCs and one MC in wastewater [19]; in Hungary, six GCs and one MC [20] and in Spain, eight GCs and one MC in river and wastewater [21]. None of the published studies monitored metabolites [22, 23] or other anthropogenic chemicals potentially affecting GC- or MC-hormone signalling [4]. For example, imidazole, triazole [24] and dithiocarbamate [25] fungicides are known to inhibit enzymes involved in corticosteroid bio-transformations [26], while certain substituted PCBs [27, 28], dibutyl-tin [29] and other organotin compounds [30] are GR inhibitors. However, GR-active PCBs and organotin compounds which are well-known EDCs could not be included in our method because, based on either their physicochemical properties or their very low environmental concentrations, they require a completely different analytical procedure. Hence, the goal of the work presented here was to develop a robust method for the analysis of all frequently applied GR- and MR-binding pharmaceuticals, including several transformation products as well as chemicals interfering with steroid genesis. Thus, up to $30 \mathrm{GCs}$ and $9 \mathrm{MCs}$, including 10 primary corticosteroid metabolites, and 14 nonsteroidal compounds (see Table 1) were selected. We show that the method is applicable to different matrices such as untreated wastewater, treated wastewater and river water. To our knowledge, this method allows monitoring the most complete selection of compounds expected to interfere with the GC- and MChormone signalling pathways.

\section{Experimental part}

\section{Chemicals and solutions}

Standard compounds (STD) were obtained from SigmaAldrich and deuterated internal standards (IS) from CDN isotopes (Dr. Ehrenstorfer, Augsburg; see Table 1). They were used without further purification to prepare standard solutions in ethanol stored at $-20{ }^{\circ} \mathrm{C}$. The structures of the steroidal compounds are given in Table 2. Organic solvents were of HPLC gradient-grade purity from Acros or Scharlau.

\section{Sample collection}

Wastewater from a hospital (Kantonsspital Aarau, Baden, Switzerland), a wastewater treatment plant (WWTP, Baden) and water from two rivers were sampled. Hospital wastewater outflow and WWTP influent and effluent were collected time proportionally: hospital wastewater during $3 \mathrm{~h}(250 \mathrm{~mL}$ every $10 \mathrm{~min}$ ) and the others by a built-in WWTP auto-sampling device during 6-8 h. River water (Limmat) was obtained from four grab samples upstream $(1.4 \mathrm{~km})$ and downstream $(1.6 \mathrm{~km})$ of the WWTP, and from a second river (Thur at Frauenfeld) running through agricultural land but $5.0 \mathrm{~km}$ downstream of a small WWTP. Samples were cooled during transport to the lab. Purified water (18 M $\Omega$ ) handled like a sample provided the solutions for method blank values.

\section{Sample preparation and solid-phase extraction}

Samples were spiked with five deuterated IS (Table 1, $100 \mathrm{ng} /$ $\mathrm{L}$ each). River water $(1 \mathrm{~L})$, wastewater effluent $(1 \mathrm{~L})$, and untreated wastewater $(0.5 \mathrm{~L})$ were filtered through glass fibre (GF/F $(0.7 \mu \mathrm{m})$, Whatmann) the same day of sampling and stored at $4{ }^{\circ} \mathrm{C}$ in the dark. Ammonium formate was added to the samples to reach $15 \mathrm{mM}$ and $\mathrm{pH} 6.50-6.85$, and solidphase extraction (SPE) was performed on a SPE cartridge consisting of Env+ (150 mg, Separtis), Strata-X-CW (100 mg, Phenomenex), Strata-X-AW (100 mg, Phenomenex) and Oasis HLB (200 mg, Waters). This solidphase mixture has been developed in-house and successfully applied to extract a wide range of chemicals from the water [31].

Adsorbed compounds were eluted twice with $5 \mathrm{~mL}$ acidic ( $2 \%$ formic acid) methanol/ethyl acetate $(1: 1)$. The pooled solvents were evaporated under a gentle $\mathrm{N}_{2}$ stream. The residue was transferred to a conical vial (1.5 $\mathrm{mL}$ size), and the solvent was again evaporated down to $\sim 10-20 \mu \mathrm{L}$ which then was air-dried.

Injection solutions were prepared by dissolving the residue in $30 \mu \mathrm{L}$ methanol followed by the addition of $70 \mu \mathrm{L}$ acetonitrile. This solution was diluted $1: 10$ or $1: 5$ in a 1:1 mixture of HPLC eluents A and B. 
Table 1 List of analysed corticosteroids and nonsteroidal compounds expected to interfere with the gluco- and mineralocorticoid hormone signalling pathway

\begin{tabular}{|c|c|c|c|c|c|}
\hline Name & Abbreviation & CAS & Formula & \multicolumn{2}{|c|}{ Status $\log K_{\mathrm{ow}}$} \\
\hline \multicolumn{6}{|l|}{ Glucocorticoids ${ }^{\mathrm{a}}$} \\
\hline Betamethasone & BMS & $378-44-9$ & $\mathrm{C}_{22} \mathrm{H}_{29} \mathrm{FO}_{5}$ & STD & 2.0 \\
\hline Betamethasone D5 & BMS D5 & - & $\mathrm{C}_{22} \mathrm{H}_{24} \mathrm{D}_{5} \mathrm{FO}_{5}$ & IS & 2.0 \\
\hline Budesonide & $\mathrm{BDN}$ & $51333-22-3$ & $\mathrm{C}_{25} \mathrm{H}_{34} \mathrm{O}_{6}$ & STD & 3.2 \\
\hline Clobetasol & CBS & $25122-41-2$ & $\mathrm{C}_{22} \mathrm{H}_{28} \mathrm{C}_{1} \mathrm{FO}_{4}$ & STD & 2.5 \\
\hline Clobetasol propionate & CBP & $25122-46-7$ & $\mathrm{C}_{25} \mathrm{H}_{32} \mathrm{C}_{1} \mathrm{FO}_{5}$ & STD & 3.5 \\
\hline Clobetasol propionate, HO- & $\mathrm{CBP} \mathrm{OH}$ & - & $\mathrm{C}_{25} \mathrm{H}_{32} \mathrm{C}_{1} \mathrm{FO}_{6}$ & & - \\
\hline Corticosterone & $\mathrm{CRC}$ & $50-22-6$ & $\mathrm{C}_{21} \mathrm{H}_{30} \mathrm{O}_{4}$ & STD & 1.9 \\
\hline Cortisone & CRT & $53-06-5$ & $\mathrm{C}_{21} \mathrm{H}_{28} \mathrm{O}_{5}$ & STD & 1.5 \\
\hline Cyproterone acetate & CYP & $427-51-0$ & $\mathrm{C}_{24} \mathrm{H}_{29} \mathrm{C}_{1} \mathrm{O}_{4}$ & & - \\
\hline Desonide & DSN & $638-94-8$ & $\mathrm{C}_{24} \mathrm{H}_{32} \mathrm{O}_{6}$ & & - \\
\hline Dexamethasone & DMS & $50-02-2$ & $\mathrm{C}_{22} \mathrm{H}_{29} \mathrm{FO}_{5}$ & STD & 1.8 \\
\hline Dexamethasone-21-acetate & DMS 21-ac & $1177-87-3$ & $\mathrm{C}_{24} \mathrm{H}_{31} \mathrm{FO}_{6}$ & STD & 2.9 \\
\hline DMS, HO-/BMS, HO- & & - & $\mathrm{C}_{22} \mathrm{H}_{29} \mathrm{FO}_{6}$ & & - \\
\hline Flumetasone & FMS & $2135-17-3$ & $\mathrm{C}_{22} \mathrm{H}_{28} \mathrm{~F}_{2} \mathrm{O}_{5}$ & STD & 1.9 \\
\hline Fluorometholone & FMT & $426-13-1$ & $\mathrm{C}_{22} \mathrm{H}_{29} \mathrm{FO}_{4}$ & STD & 2.0 \\
\hline Fluticasone propionate & FTS prop & $80474-14-2$ & $\mathrm{C}_{25} \mathrm{H}_{31} \mathrm{~F}_{3} \mathrm{O}_{5} \mathrm{~S}$ & STD & 3.7 \\
\hline Halometasone & HMS & $50629-82-8$ & $\mathrm{C}_{22} \mathrm{H}_{27} \mathrm{C}_{1} \mathrm{~F}_{2} \mathrm{O}_{5}$ & & 2.9 \\
\hline Hydrocortisone (cortisol) & HCRT & $50-23-7$ & $\mathrm{C}_{21} \mathrm{H}_{30} \mathrm{O}_{5}$ & STD & 1.7 \\
\hline Hydroxycortisol & HCRL & $3078-34-0$ & $\mathrm{C}_{21} \mathrm{H}_{30} \mathrm{O}_{6}$ & & - \\
\hline Medroxyprogesterone & MPG & $520-85-4$ & $\mathrm{C}_{22} \mathrm{H}_{32} \mathrm{O}_{3}$ & STD & - \\
\hline Megestrol & MGS & $3562-63-8$ & $\mathrm{C}_{22} \mathrm{H}_{30} \mathrm{O}_{3}$ & & - \\
\hline Megestrol acetate & MGS ac & $595-33-5$ & $\mathrm{C}_{24} \mathrm{H}_{32} \mathrm{O}_{4}$ & & - \\
\hline Methylprednisolone, $6 \alpha-$ & MPNL & $83-43-2$ & $\mathrm{C}_{22} \mathrm{H}_{30} \mathrm{O}_{5}$ & STD & 2.4 \\
\hline Mifepristone & MFP & $84371-65-3$ & $\mathrm{C}_{29} \mathrm{H}_{35} \mathrm{NO}_{2}$ & STD & - \\
\hline Prednisolone & PNL & $50-24-8$ & $\mathrm{C}_{21} \mathrm{H}_{28} \mathrm{O}_{5}$ & STD & 16 \\
\hline Prednisone & PNS & $53-03-2$ & $\mathrm{C}_{21} \mathrm{H}_{26} \mathrm{O}_{5}$ & STD & 1.4 \\
\hline Prednisone, HO- & PNS OH & - & $\mathrm{C}_{21} \mathrm{H}_{26} \mathrm{O}_{6}$ & & - \\
\hline Triamcinolone acetonide & TRM acetone & $76-25-5$ & $\mathrm{C}_{24} \mathrm{H}_{31} \mathrm{FO}_{6}$ & STD & 2.3 \\
\hline Triamcinolone acetonide & TRM OH acetone & - & $\mathrm{C}_{24} \mathrm{H}_{31} \mathrm{FO}_{7}$ & & - \\
\hline \multicolumn{6}{|l|}{ Mineralocorticoids $^{\mathrm{a}}$} \\
\hline Aldosterone & ALD & $52-39-1$ & $\mathrm{C}_{21} \mathrm{H}_{28} \mathrm{O}_{5}$ & STD & 1.1 \\
\hline Eplerenone & EPR & $107724-20-9$ & $\mathrm{C}_{24} \mathrm{H}_{30} \mathrm{O}_{6}$ & STD & 2.4 \\
\hline Eplerenone, $6 \beta-\mathrm{HO}$ & EPR 6-OH & - & $\mathrm{C}_{24} \mathrm{H}_{30} \mathrm{O}_{7}$ & & - \\
\hline Eplerenone, $21 \beta-\mathrm{HO}$ & EPR 21-OH & - & $\mathrm{C}_{24} \mathrm{H}_{30} \mathrm{O}_{7}$ & & - \\
\hline Fludrocortisone 21 acetate & FDCac & $514-36-3$ & $\mathrm{C}_{23} \mathrm{H}_{31} \mathrm{FO}_{6}$ & STD & 1.7 \\
\hline Hydroxyprogesterone, 21- & PGS 21-OH & $64-85-7$ & $\mathrm{C}_{21} \mathrm{H}_{30} \mathrm{O}_{3}$ & STD & 2.9 \\
\hline Progesterone & PGS & $57-83-0$ & $\mathrm{C}_{21} \mathrm{H}_{30} \mathrm{O}_{2}$ & STD & 3.8 \\
\hline Progesterone D9 & PGS D9 & $15775-74-3$ & $\mathrm{C}_{21} \mathrm{H}_{21} \mathrm{D}_{9} \mathrm{O}_{2}$ & IS & - \\
\hline Spironolactone & SRL & $52-01-7$ & $\mathrm{C}_{24} \mathrm{H}_{32} \mathrm{O}_{4} \mathrm{~S}$ & STD & 2.8 \\
\hline Spironolactone, HO- & SRL-OH & & $\mathrm{C}_{24} \mathrm{H}_{32} \mathrm{O}_{5} \mathrm{~S}$ & & - \\
\hline \multicolumn{6}{|l|}{ Nonsteroids } \\
\hline Bicalutamide & BCT & $90357-06-5$ & $\mathrm{C}_{18} \mathrm{H}_{14} \mathrm{~F}_{4} \mathrm{~N}_{2} \mathrm{O}_{4} \mathrm{~S}$ & STD & 3.4 \\
\hline Cimetidine & CMD & 51481-61-9 & $\mathrm{C}_{10} \mathrm{H}_{16} \mathrm{~N}_{6} \mathrm{~S}$ & STD & 0.5 \\
\hline Clotrimazole & CLT & $23593-75-1$ & $\mathrm{C}_{22} \mathrm{H}_{17} \mathrm{C}_{1} \mathrm{~N}_{2}$ & STD & 4.9 \\
\hline Daidzein & DIZ & $486-66-8$ & $\mathrm{C}_{15} \mathrm{H}_{10} \mathrm{O}_{4}$ & STD & 2.9 \\
\hline Daidzein D4 & DIZ D4 & $1219803-57-2$ & $\mathrm{C}_{15} \mathrm{H}_{6} \mathrm{D}_{4} \mathrm{O}_{4}$ & IS & 2.9 \\
\hline Fluconazole & $\mathrm{FCZ}$ & $86386-73-4$ & $\mathrm{C}_{13} \mathrm{H}_{12} \mathrm{~F}_{2} \mathrm{~N}_{6} \mathrm{O}$ & STD & 0.5 \\
\hline
\end{tabular}


Table 1 (continued)

\begin{tabular}{|c|c|c|c|c|c|}
\hline Name & Abbreviation & CAS & Formula & \multicolumn{2}{|c|}{ Status $\log K_{\mathrm{ow}}$} \\
\hline Fluconazole D4 & FCZ D4 & $1124197-58-5$ & $\mathrm{C}_{13} \mathrm{H}_{8} \mathrm{D}_{4} \mathrm{~F}_{2} \mathrm{~N}_{6} \mathrm{O}$ & IS & - \\
\hline Genistein & GNS & $446-72-0$ & $\mathrm{C}_{15} \mathrm{H}_{10} \mathrm{O}_{5}$ & STD & 3.0 \\
\hline Glycyrrhetinic acid & GYR & $471-53-4$ & $\mathrm{C}_{30} \mathrm{H}_{46} \mathrm{O}_{4}$ & IS & 2.7 \\
\hline Ketoconazole & KTZ & $65277-42-1$ & $\mathrm{C}_{26} \mathrm{H}_{28} \mathrm{C}_{12} \mathrm{~N}_{4} \mathrm{O}_{4}$ & STD & 3.4 \\
\hline Ketoconazole D8 & KTZ D8 & & $\mathrm{C}_{26} \mathrm{H}_{20} \mathrm{D}_{8} \mathrm{C}_{12} \mathrm{~N}_{4} \mathrm{O}_{4}$ & STD & 3.4 \\
\hline Metyrapone & MYP & $54-36-4$ & $\mathrm{C}_{14} \mathrm{H}_{14} \mathrm{~N}_{2} \mathrm{O}$ & STD & 1.4 \\
\hline Miconazole & $\mathrm{MCZ}$ & $22916-47-8$ & $\mathrm{C}_{18} \mathrm{H}_{14} \mathrm{C}_{14} \mathrm{~N}_{2} \mathrm{O}$ & STD & 5.3 \\
\hline$\beta$-Naphthoflavone & NTF & $6051-87-2$ & $\mathrm{C}_{19} \mathrm{H}_{12} \mathrm{O}_{2}$ & STD & 4.9 \\
\hline Pravastatin & PRV & $81093-37-0$ & $\mathrm{C}_{23} \mathrm{H}_{36} \mathrm{O}_{7}$ & STD & 1.3 \\
\hline Quercetin & QRC & $117-39-5$ & $\mathrm{C}_{15} \mathrm{H}_{10} \mathrm{O}_{7}$ & STD & 1.8 \\
\hline Resveratrol & RVR & $501-36-0$ & $\mathrm{C}_{14} \mathrm{H}_{12} \mathrm{O}_{3}$ & STD & 2.6 \\
\hline
\end{tabular}

Status: STD: a reference compound was applied as a standard

IS internal standard

${ }^{\text {a }}$ Classifies steroids according to a potential effect on the signalling path

Chromatography

An Agilent 1100 HPLC, with the mixer column replaced by a frit, was used with in-line degasser, auto-sampler and column oven $\left(45^{\circ} \mathrm{C}\right)$ to run samples on a Poroshell 120 EC18 column $(2.1 \times 100 \mathrm{~mm}, 2.7 \mu \mathrm{m}$, Agilent) protected by a $\mathrm{C} 18$ guard column $\left(\mathrm{EC}_{18}, 2 \times 4 \mathrm{~mm}\right)$. A linear gradient $(300 \mu \mathrm{L} / \mathrm{min})$ was applied starting from 0 min with $85 \%$ A $\left(90 \% \mathrm{H}_{2} \mathrm{O}, 10 \%\right.$ acetonitrile, $\left.10 \mathrm{mM} \mathrm{NH}_{4} \mathrm{HCOO} \mathrm{pH} 5.8\right)$ and $15 \% \mathrm{~B}(10 \%$ $\mathrm{H}_{2} \mathrm{O}, 90 \%$ acetonitrile, $10 \mathrm{mM} \mathrm{NH}_{4} \mathrm{HCOO} \mathrm{pH} 6.2$ ) to $100 \%$ $\mathrm{B}$ in 21 min and back to initial condition within 1 min followed by equilibration for $4 \mathrm{~min}$. Deuterated IS compounds (see Table 1) were selected as retention time $\left(t_{\mathrm{R}}\right)$ markers, spanning the whole chromatogram.

\section{Mass spectrometry}

The column was coupled to the Turbo Spray ESI inlet of an API4000 triple quad MS (AB Sciex). The collision energy (CE) for the collision induced dissociation was optimised for each standard compound and transition. $\mathrm{ESI}^{+}$conditions were the following: needle voltage, $4500 \mathrm{~V}$; declustering potential, 20; entrance potential, 10; collision cell exit potential, 15 and interface temperature, $450{ }^{\circ} \mathrm{C}$. For each target compound, two transitions were monitored in a single reaction monitoring (SRM) mode at $\mathrm{FWHM}=0.7$ resolution during the whole chromatogram (see Tables 2 and 3). Measuring all transitions in one run gave a too long duty cycle; therefore, the samples were run twice, each with a different set of transitions (duty cycle, 1.3 and $1.6 \mathrm{~s}$, resp.), in order to get a full chromatographic track of each transition and to measure a sufficient number of data points across a chromatographic peak. Both transitions of a compound, if equally favourable, were used for quantification; otherwise, only the one with the better $\mathrm{S} / \mathrm{N}$ ratio was applied. Peak areas were calculated by Analyst 1.5 software and manually adjusted before transferring to Excel, together with the retention times, for further processing.

Data processing and evaluation

Blank values for the whole workup, pre-concentration and measurement procedure were obtained by deuterated standard addition to purified water $(1 \mathrm{~L})$, which was handled as a sample. Blank values were calculated as integrals over the expected peak base width and subtracted from samples before quantitation. Background equivalent concentrations (BEC) were calculated from blank samples and subtracted from other samples. Recoveries over the whole workup and preconcentration were obtained from five deuterated chemicals (Table 1) spiked into a blank sample. Concentrations given in Table 4 are corrected by the recovery of the nearby eluting deuterated IS. Mono-hydroxylated metabolite concentrations were calculated from parent compound calibrations. Detection limits depend on the matrix, which was different in each sample; therefore, BEC are used to calculate detection limits (DL; Table 4) as an approximation of variable DL in real samples.

\section{Results and discussions}

Target compound selection

Target compounds (see Table 1, also for abbreviations) were selected according to their role in the GC- and MC-hormone signalling pathways. GR and MR agonists and antagonists used in rather frequent medical applications were extracted 
Table 2 Structural features and experimental details of analysed steroids. MS-detection settings for SRM (Q1: precursor mass, Q3: fragment mass, CE: collision energy) and observed retention times $\left(t_{\mathrm{R}}\right)$

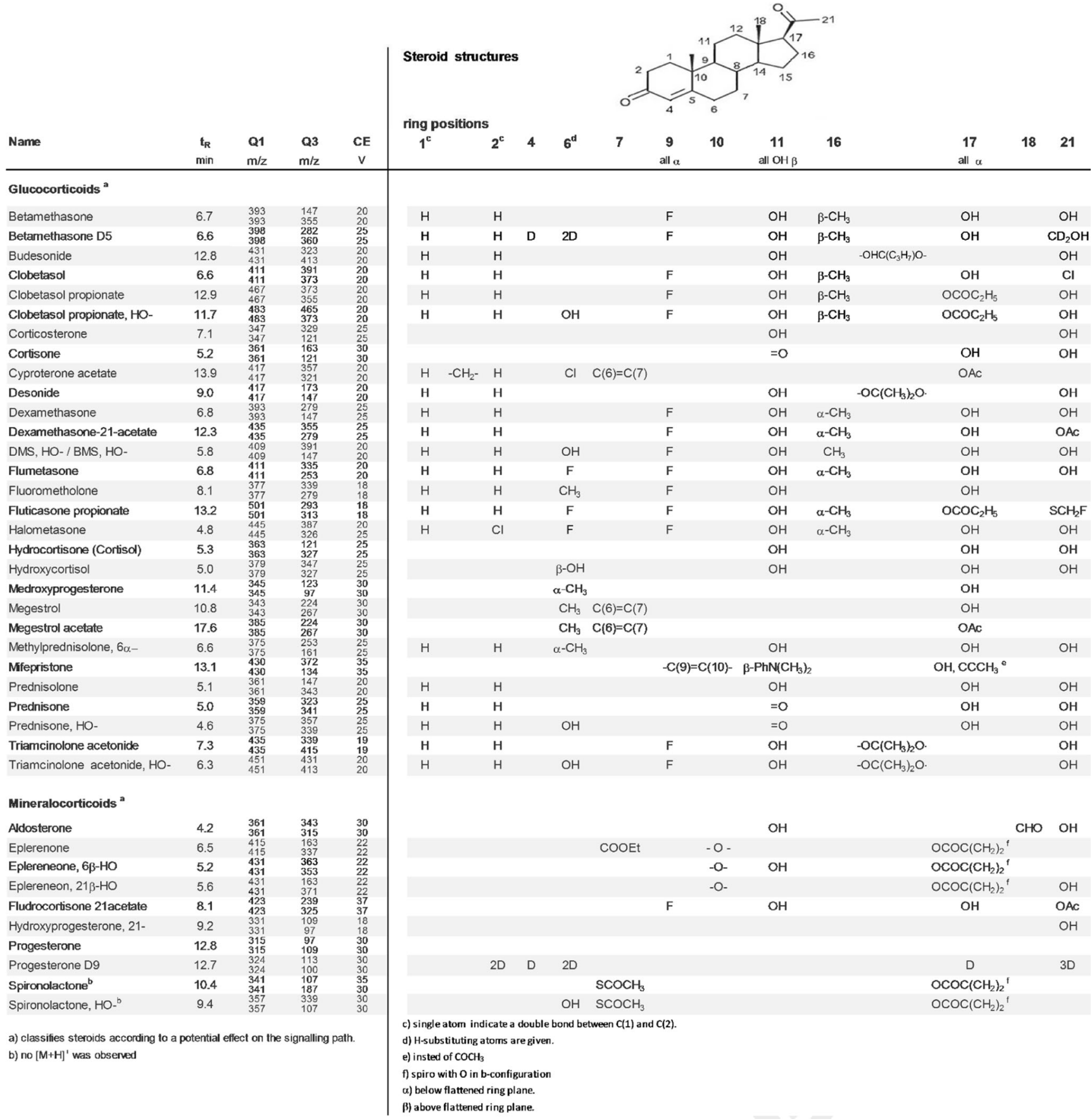

from the list of approved drugs issued by the Swiss drug approval administration (Swissmedics) [32]. These drugs are present in many human and veterinary medications. A cross reactivity between the MR and GR [33] makes it mandatory to include MCs. Quantifying both MR and GR-active compounds is therefore particularly important. For rather frequently prescribed steroids, like BMS, CBP, DMS, EPR, PGS, SRL and TRM (see Table 1), the mono-hydroxylated metabolites were included in the target list since these primary metabolites are often hydroxylated [34] at a position which only partly reduces their pharmaceutical activity (e.g. EPR [35], BDN [23]). The ratio of the original drug to its metabolites in receiving waters is largely unknown and likely variable. For instance, chemicals from topical applications and direct disposals will only be transformed in the WWTP, while ingested drugs will be metabolised in the living body before entering 
Table 3 Experimental details (for abbreviations see Table 2) of analysed nonsteroidal compounds expected to interfere with the cortico hormone signalling pathway

\begin{tabular}{|c|c|c|c|c|}
\hline Nonsteroids & $\begin{array}{c}t_{\mathrm{R}} \\
\text { Min }\end{array}$ & $\begin{array}{l}\mathrm{Q} 1 \\
m / z\end{array}$ & $\begin{array}{l}\mathrm{Q} 3 \\
\mathrm{~m} / z\end{array}$ & $\begin{array}{c}\text { CE } \\
V\end{array}$ \\
\hline \multirow[t]{2}{*}{ Bicalutamide } & \multirow[t]{2}{*}{10.2} & 431 & 217 & 20 \\
\hline & & 431 & 187 & 20 \\
\hline \multirow[t]{2}{*}{ Cimetidine } & \multirow[t]{2}{*}{0.6} & 253 & 117 & 18 \\
\hline & & 253 & 159 & 18 \\
\hline \multirow[t]{2}{*}{ Clotrimazole $^{\mathrm{a}}$} & \multirow[t]{2}{*}{13.5} & 277 & 165 & 30 \\
\hline & & 277 & 241 & 30 \\
\hline \multirow[t]{2}{*}{ Daidzein } & \multirow[t]{2}{*}{4.1} & 255 & 137 & 37 \\
\hline & & 255 & 199 & 37 \\
\hline \multirow[t]{2}{*}{ Daidzein D4 } & \multirow[t]{2}{*}{4.2} & 259 & 231 & 37 \\
\hline & & 259 & 203 & 37 \\
\hline \multirow[t]{2}{*}{ Fluconazole } & \multirow[t]{2}{*}{1.8} & 307 & 220 & 30 \\
\hline & & 307 & 238 & 30 \\
\hline \multirow[t]{2}{*}{ Fluconazole D4 } & \multirow[t]{2}{*}{1.7} & 311 & 243 & 25 \\
\hline & & 311 & 224 & 25 \\
\hline \multirow[t]{2}{*}{ Genistein } & \multirow[t]{2}{*}{6.0} & 271 & 153 & 40 \\
\hline & & 271 & 215 & 40 \\
\hline \multirow[t]{2}{*}{ Glycyrrhetinic acid } & \multirow[t]{2}{*}{14.3} & 471 & 177 & 45 \\
\hline & & 471 & 135 & 50 \\
\hline \multirow[t]{2}{*}{ Ketoconazole } & \multirow[t]{2}{*}{10.8} & 531 & 489 & 45 \\
\hline & & 244 & 45 & 531 \\
\hline \multirow[t]{2}{*}{ Ketoconazole D8 } & \multirow[t]{2}{*}{10.9} & 539 & 497 & 45 \\
\hline & & 539 & 185 & 45 \\
\hline \multirow[t]{2}{*}{ Metyrapone } & \multirow[t]{2}{*}{4.0} & 227 & 121 & 25 \\
\hline & & 227 & 106 & 25 \\
\hline \multirow[t]{2}{*}{ Miconazole } & \multirow[t]{2}{*}{16.1} & 417 & 159 & 35 \\
\hline & & 417 & 161 & 35 \\
\hline \multirow[t]{2}{*}{$\beta$-Naphthoflavone } & \multirow[t]{2}{*}{14.1} & 273 & 171 & 38 \\
\hline & & 273 & 129 & 38 \\
\hline \multirow[t]{2}{*}{ Pravastatin $^{\mathrm{a}}$} & 12.7 & 469 & 263 & 32 \\
\hline & & 469 & 187 & 32 \\
\hline Quercetin & 12.5 & 303 & 153 & 35 \\
\hline & & 303 & 137 & 35 \\
\hline Resveratrol & 10.6 & 229 & 136 & 20 \\
\hline & & 229 & 195 & 2 \\
\hline
\end{tabular}

${ }^{\mathrm{a}}$ No $[\mathrm{M}+\mathrm{H}]+$ was observed

the WWTP via excretion. Another reason to include metabolites is the fact that some drugs are sold as inactive forms (e.g. cortisone, prednisone), so-called prodrugs, which are easily transformed to active compounds (hydrocortisone (cortisol), prednisolone). Other prodrugs contain readily hydrolysable side chains that facilitate the uptake (e.g. acetate, propionate; see Table 2).

Odermatt et al. [36, 4] reported on a large number of nonsteroidal environmental chemicals that could potentially affect GC- and MC-hormone signalling pathways. Based on these considerations, specific enzyme inhibitors of the steroid biosynthesis and biotransformation have been included in the target list for the current work because an impairment of these enzymes also contributes to the overall disruption of pathways of interest [36]. The analysed nonsteroids (listed in Table 1) represent a large variety of chemicals acting as phytohormones and enzyme inhibitors (fungicides, lipid lowering drugs) or being used as dietary supplements and flavours.

\section{Solid-phase extraction}

The targets included in this study are compounds of diverse polarities spanning 5 orders of magnitude in $\log K_{\text {ow }}$ (Table 1). They were successfully extracted and enriched by a mixture of commercially available extraction phases in a single-step multimode SPE cartridge [37], circumventing multiple laborious single extraction steps each geared to a specific substance class.

Some eluted cartridges have further been extracted by solvents of decreasing polarity similarly to the fractionation procedure reported for steroid metabolomics in tissues [38]. Acidified methanol/ethyl acetate recovered acidic polar to medium-polar compounds in the first fraction. Thereafter, basic ethyl acetate methanol (1:1, $2 \%$ ammonia) was applied to elute strongly basic, if any, polar compounds. A third faction was obtained by eluting with ethyl acetate alone and a fourth by cyclohexane which could remobilize increasingly lipophilic compounds from the cartridges. Fractionating elution reduces the matrix content in a fraction and thus leads to less ion suppression and interferences during detection. However, the analysis of these fractions showed that all standard compounds eluted in the first fraction (50-100\%) and that only the basic compounds, miconazole and ketoconazole, were found in fraction 2 (up to $50 \%$ ). Other concentrations found in fraction 2 of a hospital wastewater sample were low (generally ten times lower than in fraction 1). These findings justify our decision to analyse exclusively fraction 1 by LCMS/MS. Possible losses are accounted for by the deuterated IS. Pre-concentration factors of 1000 for less matrix containing samples (river water, WWTP effluent) and 500 for samples with higher matrix content (nontreated wastewater) were used.

Recoveries from the blank solutions (30-80\%, calculation based on the IS) were comparable or slightly lower than those found in the samples (36-100 \%), possibly due to the higher ionic strength in the samples which forces analytes into the organic phase. The mixed-mode phase is optimal for coextracting different compound classes but gave a broad recovery range similar to the one reported (25-82\%) for ten GCs eluted from Oasis HLB phase using AcOEt and from Isolute $\mathrm{ENV}+$ using methanol [21]. While methanol is required to elute the more polar nonsteroids, it is a less suitable solvent for corticosteroids. This might explain the broad recovery range. 
Table 4 Concentrations (ng/L) found in Swiss rivers and wastewaters. Values from three river waters are given as a range. Detection limits apply for river waters

\begin{tabular}{|c|c|c|c|c|c|}
\hline \multirow[t]{2}{*}{ Name } & \multirow[t]{2}{*}{ DL } & \multicolumn{3}{|c|}{ Waste waters } & \multirow[t]{2}{*}{ River waters } \\
\hline & & Hospital & WWTP inflow & WWTP effluent & \\
\hline \multicolumn{6}{|l|}{ Glucocorticoids } \\
\hline Betamethasone + dexamethasone & $<2$ & 1720 & 106 & 15 & $8-13$ \\
\hline BMS, DMS, 21acetate & $<1$ & 4 & $<2$ & 4 & $<1-13$ \\
\hline $\mathrm{BMS},-\mathrm{HO}+\mathrm{DMS},-\mathrm{HO}$ & $(<1)$ & $(40)$ & (34) & (19) & $(10-14)$ \\
\hline Budesonide & $<0.5$ & 4 & 1 & $<1$ & $1-4$ \\
\hline Clobetasol & $<0.5$ & 1 & 4 & $<1$ & $<0.5-1$ \\
\hline Clobetasol propionate & $<0.5$ & 7 & 7 & $<1$ & $<1$ \\
\hline Clobetasol propionate $\mathrm{HO}$ & $(<0.5)$ & $(10)$ & $(5)$ & $(<1)$ & $(<1-3)$ \\
\hline Corticosterone & $<1$ & 14 & 21 & 5 & $4-6$ \\
\hline Cyproterone acetate & $(<0.5)$ & $(27)$ & $(<1)$ & $(<1)$ & $(<1)$ \\
\hline Desonide & $(<0.5)$ & $(<1)$ & $(<1)$ & $(<1)$ & $(<1)$ \\
\hline Flumetasone & $<1$ & 5 & 6 & 3 & $1-2$ \\
\hline Fluorometholone & $<0.5$ & 2 & 3 & $<1$ & $<0.5-1$ \\
\hline Fluticasone propionate & $<0.5$ & 5 & 4 & $<1$ & $<1$ \\
\hline Halometasone & $(<0.5)$ & (8) & $(<1)$ & (1) & $(1-5)$ \\
\hline Hydrocortisone + cortisone & $<5$ & 378 & 160 & 26 & $7-10$ \\
\hline Hydroxycortisol, $6 \beta-$ & $(<5)$ & $(<10)$ & $(<10)$ & $(<10)$ & $(<4)$ \\
\hline Medroxyprogesterone & $<1$ & 42 & 6 & $<2$ & $1-5$ \\
\hline Megestrol & $(<0.5)$ & (17) & (69) & $(<1)$ & $(1-2)$ \\
\hline Megestrol acetate & $(<0.5)$ & (11) & $(<1)$ & $(<1)$ & $(<1)$ \\
\hline Methylprednisolone, $6 \alpha-$ & $<0.5$ & 36 & 8 & 1 & $3-5$ \\
\hline Mifepristone & $<1$ & 17 & $<2$ & $<1$ & $<1$ \\
\hline Prednisolone + prednisone & $<4$ & 1221 & 336 & $<5$ & $10-12$ \\
\hline Prednisolone + prednisone & $(<4)$ & $(616)$ & $(843)$ & $(18)$ & $(4-45)$ \\
\hline Triamcinolone acetonide & $<1$ & 14 & 6 & 1 & $<1$ \\
\hline Triamcinolone acetonide $\mathrm{HO}$ & $(<1)$ & $(54)$ & (2) & $(<1)$ & $(<1)$ \\
\hline \multicolumn{6}{|l|}{ Mineralocorticoids } \\
\hline Aldosterone & $<1$ & 22 & 19 & 2 & $<1-2$ \\
\hline Eplerenone & $<1$ & 11 & 6 & 4 & $2-3$ \\
\hline Eplerenone, 21-HO & $(<0.5)$ & $(25)$ & (34) & $(<1)$ & $(1-2)$ \\
\hline Eplerenone, $6 \beta-\mathrm{HO}$ & $(<0.5)$ & (9) & (4) & (2) & $(1-3)$ \\
\hline Fludrocortisone acetate & $<1$ & 82 & 36 & 12 & $5-14$ \\
\hline Hydroxyprogesterone, 21- & $<1$ & 11 & 5 & $<2$ & $1-3$ \\
\hline Progesterone & $<1$ & 15 & 4 & $<1$ & $4-10$ \\
\hline Spironolactone & $<1$ & 130 & 36 & 2 & $1-4$ \\
\hline Spironolactone $\mathrm{OH}$ & $(<1)$ & $(217)$ & $(315)$ & $(<2)$ & $(<1-2)$ \\
\hline \multicolumn{6}{|l|}{ Nonsteroids } \\
\hline Cimetidine & $<0.5$ & 5 & 5 & 2 & $<0.5-2$ \\
\hline Clotrimazole & $<2$ & 17 & 27 & 23 & $31-47$ \\
\hline Daidzein & $<2$ & 671 & 1538 & $<3$ & $<2$ \\
\hline Fluconazole & $<2$ & 4640 & 236 & 200 & $4-18$ \\
\hline Fluconazole & $<1$ & 456 & 2049 & 28 & $5-8$ \\
\hline Glycyrrhetinic acid & $<8$ & 2829 & 85 & 13 & $<8-23$ \\
\hline Ketoconazole & $<0.5$ & 4 & 142 & 15 & $<1$ \\
\hline Metyrapone & $<5$ & $<10$ & $<10$ & $<5$ & $<5$ \\
\hline Miconazole & $<0.5$ & 2 & 15 & $<1$ & $<1$ \\
\hline
\end{tabular}


Table 4 (continued)

\begin{tabular}{lccccc}
\hline Name & DL & \multicolumn{2}{l}{ Waste waters } & & \multirow{2}{*}{ River waters } \\
\cline { 3 - 6 } & & Hospital & WWTP inflow & WWTP effluent \\
\hline B-Naphthoflavone & $<0.5$ & 1 & $<1$ & $<1$ & $<0.5-1$ \\
Pravastatin & $<5$ & 69 & 39 & $<5$ & $<5-8$ \\
Quercetin & $<100$ & $<200$ & $<200$ & $<100$ & $<150$ \\
Resveratrol & $<150$ & $<300$ & $<300$ & $<150$ \\
\hline
\end{tabular}

Values in brackets were calculated from a calibration with a STD compound of similar but not identical structure (see text)

Fluconazole, eluting 1 min after the void volume, was the only deuterated IS showing higher than $100 \%$ recoveries in wastewater. Similar recoveries from pure water and from samples confirm that ion suppression in the ESI source and/or contribution from interfering masses must either be balanced or are basically absent, except for compounds from wastewater samples eluting near the front. These samples always contain a larger number of in front eluting compounds causing interferences compared to less matrix-loaded samples.

\section{Chromatography}

Usually, for highest separation efficiency, UPLC is applied with column-packing material of less than $2 \mu \mathrm{m}$ diameter and backpressures above 400 bar. Since these conditions exceed the pressure limit of our pump, we used a core shell column material $(2.7 \mu \mathrm{m})$ which provides a separation similar to UPLC but, in combination with the low viscosity of acetonitrile at $45{ }^{\circ} \mathrm{C}$, considerably less backpressure ( $<250$ bar). A linear gradient starting at $18 \%$ acetonitrile and running up to $90 \%$ within 20 min sufficiently separated all the compounds in $18 \mathrm{~min}$. Herrero et al. recently reported a shorter run time (13 min) for nine GCs only [21] on a $50 \times 4.6 \mathrm{~mm}$ column and $1 \mathrm{~mL} / \mathrm{min}$ at $50^{\circ}$. In another publication, acetonitrile was reported to be the best solvent for an efficient separation and lower backpressure, while 2-propanol provided higher response for cortisol in ESI MS [39]. In our setup, however, 2propanol produced too high a backpressure and a suboptimal separation, which is why, despite the higher sensitivity, we refrained from using it. The applied acetonitrile gradient provided stable retention times (e.g. triamcinolone acetonide at $t_{\mathrm{R}}=7.40 \mathrm{~min}, \mathrm{STDEV}=0.02 \mathrm{~min}, n=78$ ), an important criterion for compound identification. The separation of STD compounds is shown in Fig. 1 and retention times are given in Tables 2 and 3. Retention time windows were determined experimentally for standards. For compounds where no standard was available, retention time windows were estimated based on the experimentally determined $t_{\mathrm{R}}$ of the most similar STD compound or in analogy to published data. For the $t_{R}$ assignment of mono-hydroxylated corticosteroid transformation products, a $t_{\mathrm{R}}$ difference between parent and product compound similar to that published for EPR and EPR-OH [35] was assumed. Retention times of matrix-free STD mixtures and environmental samples did not show any shift due to the matrix. All in all, the short mass transfer on the core shell particles provided a high separation efficiency.

\section{Mass spectrometry}

In order to find the most sensitive transition for each STD compound, their fragmentation behaviour was investigated using different collision energies at varying acetonitrile content $(20-80 \%)$. The generated main fragments agreed well with literature data. Some changes in relative intensities were observed for lowest acetonitrile contents which did not drastically reduce sensitivity. ESI detection of corticoids in positive ion mode $\left([\mathrm{M}+\mathrm{H}]^{+}\right)$has been reported to provide a higher response than in the negative ion mode [38, 7]. This was confirmed by our own experiments. Both formic acid and ammonium formate were evaluated as proton donors in $\mathrm{ESI}^{+}$, but almost no difference could be observed. The ammonium formate salt with the $\mathrm{pH}$ adjusted to close to neutral was preferred since some of the compounds are not stable under strongly acidic conditions in combination with an elevated column temperature. Two precursor-fragment ion transitions were monitored for each compound. For SRL, CLT and PRV, no $[\mathrm{M}+\mathrm{H}]^{+}$was observable. SRL and SRL-OH readily lost thioacetic acid, so that only the resulting $\mathrm{M}-\mathrm{CH}_{3} \mathrm{COSH}$ ion $(\mathrm{m} / \mathrm{z} 341$ and 357$)$ was available as precursor ion instead. The imidazole ring was cleaved off from CLT, yielding the mono-chlorinated triphenylmethane fragment $(\mathrm{m} / \mathrm{z} 277)$ as precursor, while PRV was detected as its formate adduct only.

\section{Method performance}

The method was developed using 38 standard compounds and 5 deuterated IS compounds (see Table 1) selected to cover the whole chromatographic run time. Their measured properties $\left(t_{\mathrm{R}}\right.$, fragmentation pattern) and literature data served as the basis for deducing retention times and transitions for targets not purchased as STD compounds (see Table 1). Among the initial non-STD targets, dexamethasone-21-acetate, 


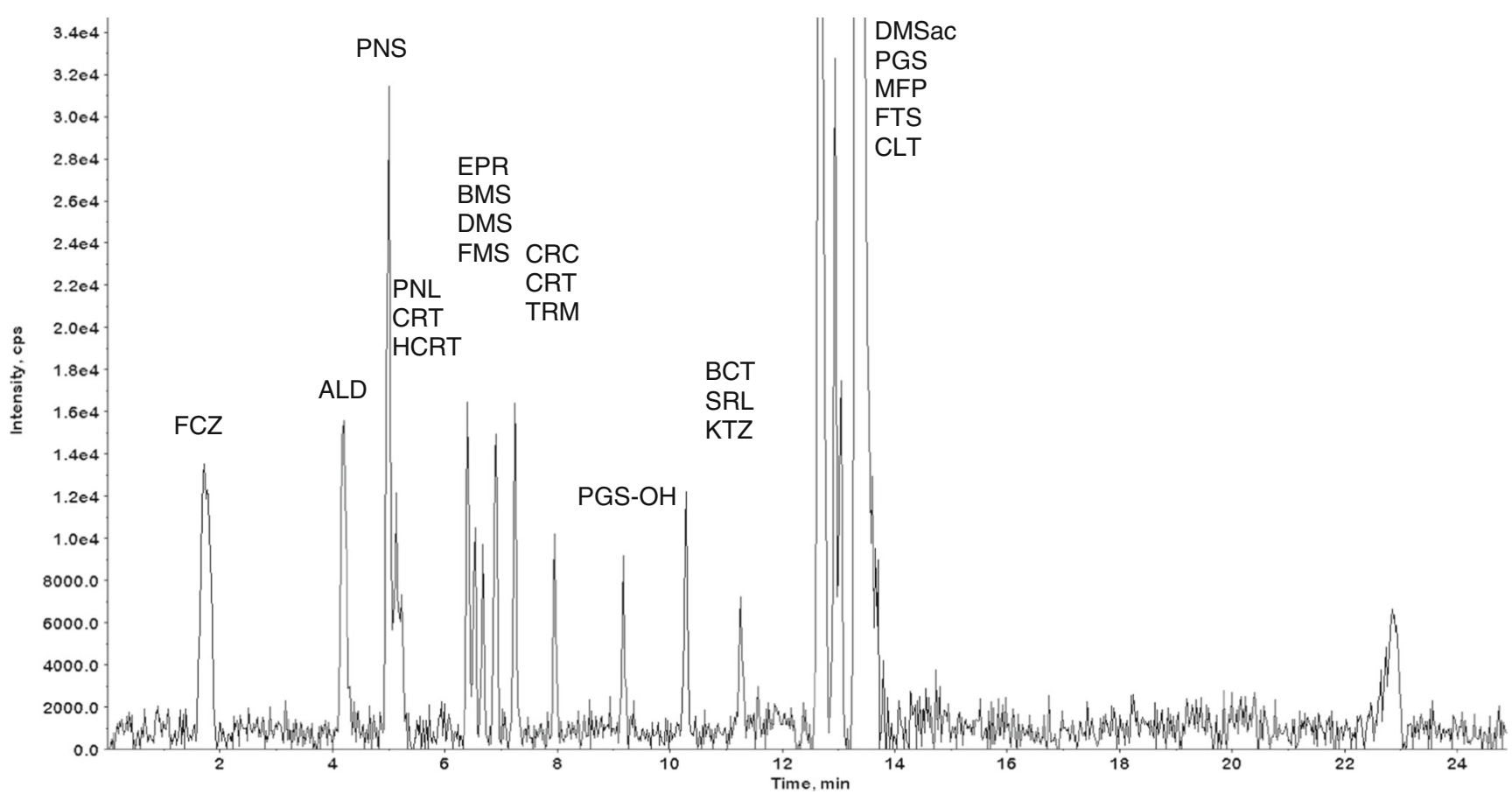

Fig. 1 Overlaid chromatograms detecting 22 compounds by 66 SRMs in a mixture of 34 STD compounds. Chromatograms were background subtracted but not smoothed

budesonide and $6 \alpha$-methylprednisolone were detected at significant concentrations in environmental samples and for this reason were purchased too for reliable quantification. Bicalutamid was not stable in diluted STD compound mixtures and was therefore not quantified.

For surface waters, BEC multiplied by 5 were used to represent DL which are in the few nanograms per litre range for all of the compounds (Table 4), except for the less stable flavones, quercetin and resveratrol. For samples with a higher matrix load, BEC multiplied by 10 approximates DL more realistically. Stable $t_{\mathrm{R}}$ allowed to accept peaks only within a narrow $( \pm 0.1 \mathrm{~min}) t_{\mathrm{R}}$ window, and monitoring two collision energy optimised transitions per target analyte provided a reliable compound identification. The concentrations determined (see Table 4) are adequately validated by referencing to appropriate deuterated IS and the use of structurally identical calibration standards for quantification.

The similarity of the steroidal structures (see Table 2), producing similar or identical fragments, is prone to cross contributions from insufficiently separated analytes. The critical cases encountered are listed in Table 5. Aldosterone, cortisone and prednisolone have the same isobaric protonated molecule ions ( $\mathrm{m} / \mathrm{z}$ 361.3). ALD has a significantly different retention time and hence cannot contribute to the CRT and PNL fragments and vice versa. CRT and PNL are co-eluting; however, CRT does not produce fragment $\mathrm{m} / \mathrm{z} 147$ at CE 20 used to quantify PNL, and PNL does not produce fragment $\mathrm{m} /$ $z 163$ at CE 30 which is used to quantify CRT. Hence, all three compounds can be quantified without cross contribution.
Other cross sensitivities have been investigated under increasing concentrations (10-20-fold) of the possible contributor but were negligible in most cases. For instance, PNS contributed $1.7 \%($ per $\mu \mathrm{g} / \mathrm{mL})$ to PNL, whereas EPR contributed $1.2 \%$ to D5-betamethasone due to the overlapping isotope pattern. However, closely eluting and the same fragment forming pairs like HCRT/CRT and PNL/PNS showed a much higher cross contribution. The intensity of the CRT transition $361 \rightarrow 163$ was composed of up to $40 \%$ by the HCRT transition $363 \rightarrow$ 163, and PNL contributed $6.0 \%$ to PNS, which is not possible
Table 5 Sets of compounds with similar or identical $[\mathrm{M}+\mathrm{H}]^{+} \mathrm{m} / \mathrm{z}$ values and retention times

\begin{tabular}{lccc}
\hline Compound & Q1 & Q3 & $t_{\mathrm{R}}$ \\
\hline Prednisone & 359 & 341 & 5.0 \\
Prednisone & 359 & 323 & 5.0 \\
Aldosterone & 361 & 343 & 4.2 \\
Aldosterone & 361 & 315 & 4.2 \\
Prednisolone & 361 & 343 & 5. \\
Prednisolone & 361 & 147 & 5.1 \\
Cortisone & 361 & 163 & 5.1 \\
Cortisone & 361 & 121 & 5.1 \\
Hydrocortisone & 363 & 121 & 5.3 \\
Hydrocortisone & 363 & 327 & 5.3 \\
Betamethasone & 393 & 147 & 6.7 \\
Betamethasone & 393 & 355 & 6.7 \\
Dexamethasone & 393 & 147 & 6.8 \\
Dexamethasone & 393 & 279 & 6.8 \\
\hline
\end{tabular}


by an overlapping isotope pattern but, in this case, must be due to an ESI insource reduction of the alcohol to the ketone. Such pairs require a ratio around $1: 1$ or a better separation between the two to be quantified separately.

Therefore, closely eluting compounds producing the same fragments (e.g. BMS and DMS [40]) cannot be assigned unambiguously if in a sample only one single peak appears close to the expected $t_{\mathrm{R}}$. Even small $t_{\mathrm{R}}$ variations can make the assignment uncertain. The peaks can be allocated correctly only when both compounds are present approximately in the same concentrations. As this is not the case in all samples, the peak integration window was selected wide enough to integrate both compounds. Accordingly, the following pairs are quantified as the sum of two compounds: PNS/PNL, CRT/HCRT and BMS/ DMS and accordingly BMS 21-ac/DMS 21-ac (see Table 4).

For 16 compounds, finally, we did not work with identical standard compounds (see Table 1) because they were not available or too expensive in relation to their relevance. The concentrations of these compounds were calculated from a calibration of a standard with similar structure and therefore cannot be considered as accurate concentrations (indicated by brackets in Table 4). These values are useful as indicators of low or high possible concentrations but can be correctly determined only by using the corresponding standard compounds.

Mono-hydroxylated metabolites showed in most cases significantly higher concentrations than their parent compounds. Although no reference metabolites were available, it can reasonably be assumed that their chemical behaviour and hence MS response is similar to their parent compound. Also the correct identification of the mono-hydroxylated metabolites is highly probable since, beside the two monitored transitions, the expected $t_{\mathrm{R}}$ difference to their precursor corresponds exactly to the one found for EPR and EPR-OH, both were structurally identified [35].

\section{Application}

The method presented was applied in a first-trial campaign to analyse wastewaters and their corresponding receiving river waters [41]. Concentrations found in river waters are summarised in Table 4, and typical chromatograms are shown in Fig. 2. Lowest analyte concentrations, mostly around or below detection limits, were found in river waters, and samples from different locations did not show relevant concentration differences. This is likely due to a large dilution and good mixing of WWTP effluents with river water. Nevertheless, several GCs/MCs reach concentrations around $10 \mathrm{ng} / \mathrm{L}$ in river waters and the two nonsteroids enzyme inhibitors fluconazole and clotrimazole reach even higher concentrations. The two are used as fungicides in many approved over-the-counter drug preparations (53 in Switzerland [32]), including non-GC and non-MC medications. All the compounds measured here in river water samples add up to around $200 \mathrm{ng} / \mathrm{L}$, which are clearly in the range (100-1000 ng/L), producing increased glucose levels and decreased leucocytes in fathead minnows [9].

The concentration differences between treated WWTP effluent (see Table 4 and Fig. 3) and nontreated WWTP inflow

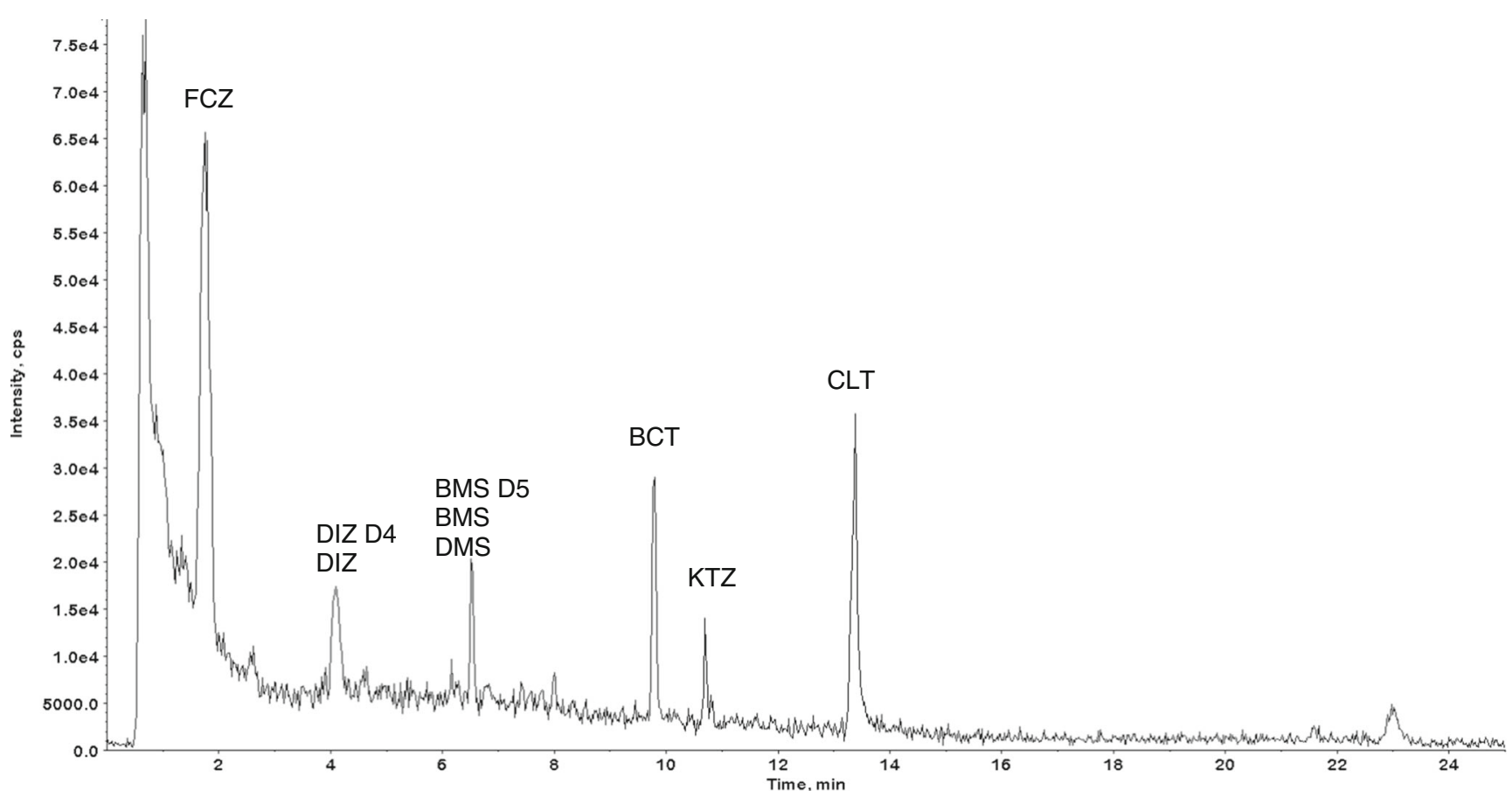

Fig. 2 Overlaid chromatograms of identified compounds in a river water sample. Chromatograms were not background subtracted and not smoothed 

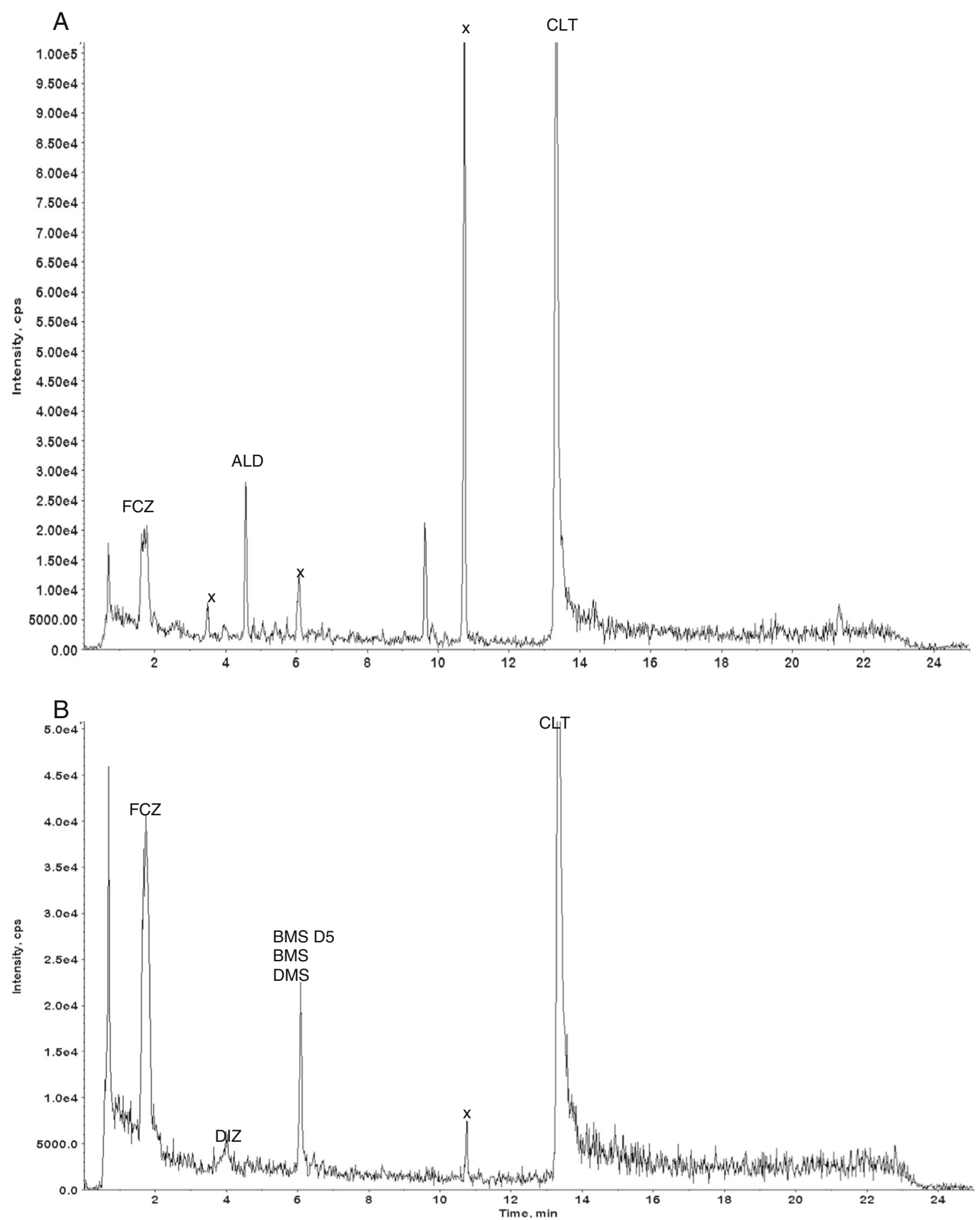

Fig. 3 Overlaid chromatograms of identified compounds in wastewater, a WWTP inflow sample (a) and a treated wastewater sample (b, WWTP effluent). Chromatograms were background subtracted but not smoothed and peaks denoted by $x$ are not due to target compound

are also evident. However, eight compounds are eliminated only by $50-80 \%$ during the treatment which parallels the findings of an insufficient decrease of biological glucocorticoid activities in an EDC study on Swiss wastewater treatment plants [15]. As expected, high concentrations were observed in untreated wastewater (see Table 4 and Fig. 3b), the highest in hospital wastewater with lowest dilution and no elimination. Steroid metabolization already occurred to a large extent since mono-hydroxylated derivatives are present at high concentrations and the ratio to their precursor further increases until the compounds reach the WWTP. However, a single combined sample over $4 \mathrm{~h}$ might not be representative for the general use of pharmaceutical in this hospital over a longer time [42]. 


\section{Conclusions}

The results show that the developed method is well suited to analyse a large number of diverse chemicals acting on the corticoid signalling pathway, be that by direct interaction with nuclear receptors or steroid genesis. The high separation efficiency and sensitivity of the developed LC-MS method allows determining these compounds with the high sensitivity (ng/L) required for the low concentrations typically found in diverse environmental matrices. The work presented also shows that primary corticosteroid metabolites not monitored thus far and some nonsteroids are indeed released together into the environment. The concentration level they reach together with several GCs and MCs suggests a disruption of the GC- and MC-hormone signalling pathways in aquatic organisms is most likely. Furthermore, halogenated corticosteroids and their esters are likely to be the main contributors to the corticoid-like activities found in environmental waters due to their higher stability, higher potency and lower elimination rate. For assessing the environmental risks, the biological activity of all the compounds found has to be known. More work is needed to reveal effects of a mixture of corticoids, its primary metabolites and higher concentrated fungicides in disturbing the corticosteroid signalling pathway. Single chemical compound analysis, as described here, needs to be combined with an assay for biological effects.

Acknowledgments The authors are thankful for the financial support by the Sciex-NMSch fund (P. Macikova) and the Swiss Federal Office for the Environment (FOEN).

\section{References}

1. Toppari J, Skakkebaek NE (1998) Sexual differentiation and environmental endocrine disrupters. Baillieres Clin Endocrinol Metab 12(1):143-156

2. Schubert S, Peter A, Burki R, Schonenberger R, Suter MJF, Segner H, Burkhardt-Holm P (2008) Sensitivity of brown trout reproduction to long-term estrogenic exposure. Aquat Toxicol 90(1):65-72

3. Scholz S, Kluver N (2009) Effects of endocrine disrupters on sexual, gonadal development in fish. Sex Dev 3(2-3):136-151

4. Odermatt A, Gumy C, Atanasov AG, Dzyakanchuk AA (2006) Disruption of glucocorticoid action by environmental chemicals: potential mechanisms and relevance. J Steroid Biochem Mol Biol 102(1-5):222-231

5. Odermatt A, Gumy C (2008) Glucocorticoid and mineralocorticoid action: why should we consider influences by environmental chemicals? Biochem Pharmacol 76(10):1184-1193

6. Van der Linden SC, Heringa MB, Man HY, Sonneveld E, Puijker LM, Brouwer A, Van der Burg B (2008) Detection of multiple hormonal activities in wastewater effluents and surface water, using a panel of steroid receptor CALUX bioassays. Environ Sci Technol 42(15):5814-5820

7. Schriks M, Van Leerdam JA, Van Der Linden SC, Van Der Burg B, Van Wezel AP, De Voogt P (2010) High-resolution mass spectrometric identification and quantification of glucocorticoid compounds in various wastewaters in the Netherlands. Environ Sci Technol 44(12): 4766-4774

8. Fan ZL, Wu SM, Chang H, Hu JY (2011) Behaviors of glucocorticoids, androgens and progestogens in a municipal sewage treatment plant: comparison to estrogens. Environ Sci Technol 45(7):27252733

9. Kugathas S, Sumpter JP (2011) Synthetic glucocorticoids in the environment: first results on their potential impacts on fish. Environ Sci Technol 45(6):2377-2383

10. Kugathas S, Williams RJ, Sumpter JP (2012) Prediction of environmental concentrations of glucocorticoids: the River Thames, UK, as an example. Environ Int 40:15-23

11. Duclos M (2010) Glucocorticoids: a doping agent? Endocrinol Metab Clin N Am 39(1):107-126

12. Hauri U, Hohl C (2004) Determination of clandestine corticosteroids in cosmetics with LC/DAD/MS. Mitt Lebensm Hyg 95(5):466-476

13. Kolkhof P, Borden SA (2012) Molecular pharmacology of the mineralocorticoid receptor: prospects for novel therapeutics. Mol Cell Endocrinol 350(2):310-317

14. Czock D, Keller F, Rasche FM, Haussler U (2005) Pharmacokinetics and pharmacodynamics of systemically administered glucocorticoids. Clin Pharmacokinet 44(1):61-98

15. Kienle C, Kase R, Werner I (2011) Evaluation of bioassays and wastewater quality: in vitro and in vivo bioassays for the performance review in the project "Strategy MicroPoll". Swiss centre for applied ecotoxicology. EAWAG-EPFL, Duebendorf

16. Fatta-Kassinos D, Meric S, Nikolaou A (2011) Pharmaceutical residues in environmental waters and wastewater: current state of knowledge and future research. Anal Bioanal Chem 399(1): 251-275

17. Liu S, Ying GG, Zhao JL, Chen F, Yang B, Zhou LJ, Lai HJ (2011) Trace analysis of 28 steroids in surface water, wastewater and sludge samples by rapid resolution liquid chromatography-electrospray ionization tandem mass spectrometry. J Chromatogr A 1218(10):13671378

18. Chang H, Hu J, Shao B (2007) Occurrence of natural and synthetic glucocorticoids in sewage treatment plants and receiving river waters. Environ Sci Technol 41(10):3462-3468

19. Piram A, Salvador A, Gauvrit JY, Lanteri P, Faure R (2008) Development and optimisation of a single extraction procedure for the LC/MS/MS analysis of two pharmaceutical classes residues in sewage treatment plant. Talanta 74(5):1463-1475

20. Tolgyesi A, Verebey Z, Sharma VK, Kovacsics L, Fekete J (2010) Simultaneous determination of corticosteroids, androgens, and progesterone in river water by liquid chromatography-tandem mass spectrometry. Chemosphere 78(8):972-979

21. Herrero P, Borrull F, Pocurull E, Marcé RM (2012) Determination of glucocorticoids in sewage and river waters by ultra-high performance liquid chromatography-tandem mass spectrometry. J Chromatogr A 1224:19-26

22. Spika I, Hammer S, Kleuser B, Korting HC, Schafer-Korting M (2003) Transcriptional activity of potent glucocorticoids: relevance of glucocorticoid receptor isoforms and drug metabolites. Skin Pharmacol Appl Ski Physiol 16(3):143-150

23. Matabosch X, Pozo OJ, Perez-Mana C, Farre M, Marcos J, Segura J, Ventura R (2012) Identification of budesonide metabolites in human urine after oral administration. Anal Bioanal Chem 404(2):325-340

24. Bureik M, Hubel K, Dragan CA, Scher J, Becker H, Lenz N, Bernhardt R (2004) Development of test systems for the discovery of selective human aldosterone synthase (CYP11B2) and 11bhydroxylase (CYP11B1) inhibitors. Discovery of a new lead compound for the therapy of congestive heart failure, myocardial fibrosis and hypertension. Mol Cell Endocrinol 217(1-2):249-254

25. Atanasov AG, Tam S, Rocken JM, Baker ME, Odermatt A (2003) Inhibition of 11 beta-hydroxysteroid dehydrogenase type 2 by dithiocarbamates. Biochem Biophys Res Commun 308(2):257-262 
26. Walker EA, Stewart PM (2003) 11 Beta-hydroxysteroid dehydrogenase: unexpected connections. Trends Endocrinol Metab 14(7):334 339

27. Johansson M, Nilsson S, Lund BO (1998) Interactions between methylsulfonyl PCBs and the glucocorticoid receptor. Environ Health Perspect 106(12):769-772

28. Antunes-Fernandes EC, Bovee TFH, Daamen FEJ, Helsdingen RJ, van den Berg M, van Duursen MBM (2011) Some OH-PCBs are more potent inhibitors of aromatase activity and (anti-) glucocorticoids than non-dioxin like (NDL)-PCBs and MeSO2-PCBs. Toxicol Lett 206(2):158-165

29. Gumy C, Chandsawangbhuwana C, Dzyakanchuk AA, Kratschmar DV, Baker ME, Odermatt A (2008) Dibutyltin disrupts glucocorticoid receptor function and impairs glucocorticoid-induced suppression of cytokine production. PLoS One 3(10)

30. Nakanishi T (2008) Endocrine disruption induced by organotin compounds; organotins function as a powerful agonist for nuclear receptors rather than an aromatase inhibitor. J Toxicol Sci 33(3):269-276

31. Kern S, Baumgartner R, Helbling DE, Hollender J, Singer H, Loos MJ, Schwarzenbach RP, Fenner K (2010) A tiered procedure for assessing the formation of biotransformation products of pharmaceuticals and biocides during activated sludge treatment. J Environ Monit 12(11):2100-2111

32. Swissmedic (2011) Authorized medicines, procedures and effective ingredients. http://www.swissmedic.ch/daten/00080/00251/ indexhtml?lang=en. Accessed 8 Sept 2011

33. Kohn JA, Deshpande K, Ortlund EA (2012) Deciphering modern glucocorticoid cross-pharmacology using ancestral corticosteroid receptors. J Biol Chem 287(20):16267-16275

34. Fraser R, Gower DB, Honour JW, Ingram MC, Kicman AT, Makin HLJ, Stewart PM (2010) Analysis of corticosteroids. In: Makin HLJ,
Gower DB (eds) Steroid analysis, 2nd edn. Springer, Heidelberg, pp 329-455

35. Cook CS, Berry LM, Bible RH, Hribar JD, Hajdu E, Liu NW (2003) Pharmacokinetics and metabolism of C-14 eplerenone after oral administration to humans. Drug Metab Dispos 31(11):1448-1455

36. Odermatt A (2004) Corticosteroid-dependent hypertension: environmental influences. Swiss Med Weekly 134(1-2):4-13

37. Huntscha S, Singer HP, McArdell CS, Frank CE, Hollender J (2012) Multiresidue analysis of 88 polar organic micropollutants in ground, surface and wastewater using online mixed-bed multilayer solidphase extraction coupled to high performance liquid chromatography-tandem mass spectrometry. J Chromatogr A 1268:74-83

38. Flores-Valverde AM, Hill EM (2008) Methodology for profiling the steroid metabolome in animal tissues using ultraperformance liquid chromatography-electrospray-time-of-flight mass spectrometry. Anal Chem 80(22):8771-8779

39. Han J, Kalyan S, Prior JC, Borchers CH (2011) Quantitation of urinary $6 \beta$-hydroxycortisol and free cortisol by ultra-performance liquid chromatography-quadrupole time-of-flight mass spectrometry. Clin Exp Pharmacol S2(S2):1

40. Arthur KE, Wolff JC, Carrier DJ (2004) Analysis of betamethasone, dexamethasone and related compounds by liquid chromatography/ electrospray mass spectrometry. Rapid Commun Mass Spectrom 18(6):678-684

41. Macikova P, Groh KJ, Schirmer K, Ammann AA, Suter MJF (2014) Endocrine disrupting compounds affecting corticosteroids signaling pathways in Czech and Swiss waters - potential impact on fish. submitted

42. Escher BI, Baumgartner R, Koller M, Treyer K, Lienert J, McArdell CS (2011) Environmental toxicology and risk assessment of pharmaceuticals from hospital wastewater. Water Res 45(1):75-92 